\title{
Effect of Steroid Loaded Middle Meatal Gelfoam Sheet on Endoscopic Sinus Surgery Outcome
}

\author{
Gamal Abd-Elhameed Abd-Elmaksoud, Magdy Ibrahem Gouda, Khalid Ahmed Khater* \\ Department of Otorhinolaryngology, Faculty of Medicine, Zagazig University \\ *Corresponding author: Khalid Ahmed Khater, Mobile: (+20)+201062383789, Email: kamak7@gmail.com
}

\begin{abstract}
Background: Endoscopic sinus surgery (ESS) represents the overall accepted type of surgical treatment for chronic rhinosinusitis with nasal polyposis (CRSwNP) refractory to medical treatment. Presence of postoperative Middle meatal adhesions are a potential cause of surgical failure. Triamcinolone is recently proposed as a solution for these adhesions. Objective: This study was designed to evaluate the effect of steroid loaded middle meatal gelfoam sheet on endoscopic sinus surgery outcome regarding middle meatal adhesions and synechiae formation in patients with CRSwNP refractory to medical treatment.
\end{abstract}

Patients and Methods: This prospective, randomized, single-blinded, placebo-controlled study was conducted on 62 nasal cavities of 31 patients with bilateral CRSwNP. At the end of ESS, randomly gelfoam sheet loaded with triamcinolone was placed in one middle meatus and another gelfoam sheet loaded with saline in the contralateral middle meatus for 1 week.

Results: Our results as regards topical application of steroids to the middle meatus showed a statistically significant difference between the steroid side and the saline (control) side in reduction of synechia formation after ESS. Therefore, topical application of steroids is effective in minimizing synechiae formation after ESS. It is also safe and no local or systemic complications were noted during the study.

Conclusion: Results of our study demonstrated that the steroid loaded middle meatal gelfoam sheet has a role in minimizing middle meatal adhesions and synechiae formation after endoscopic sinus surgery for patients with CRSwNP. Keywords: Steroid Loaded Middle Meatal Gelfoam Sheet, Endoscopic Sinus Surgery Outcome.

\section{INTRODUCTION}

middle-meatal spacers and showed improved early and late

Chronic rhinosinusitis (CRS) is a chronic endoscopic outcomes ${ }^{(\mathbf{8})}$.

inflammation of the sinonasal mucosa and clinically associated with 4 cardinal symptoms: nasal obstruction, drainage, a decreased sense of smell and facial pain or pressure persisting for more than 12 weeks. In some patients with CRS, massive hyperplastic inflammatory growth of nasal polyps (NP) into the nasal cavity is observed ${ }^{(1)}$. The etiology of NP is still unknown. One of the most popular theories consider polyps a consequence of conditions, which cause chronic inflammation in the sinonasal mucosa characterized by variable cellular infiltrate and stromal edema ${ }^{(2)}$. Patients having chronic rhinosinusitis with nasal polyposis (CRSwNP) refractory to medical treatment often undergo endoscopic sinus surgery (ESS) ${ }^{(3)}$.

The aim of ESS is to open the ostia of sinus and thus improve mucociliary clearance and sinus drainage pathways, as well as to facilitate the wide distribution of topical medications ${ }^{(4)}$.

Postoperative outcomes sometimes are suboptimal due to the inflammatory nature of the sinonasal mucosa leading to osteal stenosis, synechiae formation, middle turbinate lateralization and recurrent polyposis (5). Postoperative adhesions in the middle meatus decrease sinus ventilation and mucus drainage leading to persistant symptoms ${ }^{(6)}$. Therefore, the patency of the antrostomy site and minimizing mucosal inflammation are significant targets during early postoperative care for better outcome. Common treatment forms involve topical nasal steroid sprays, off-label topical steroid formulations and systemic steroids ${ }^{(7)}$. Adequate drug delivery and patient compliance are more provided by topical steroid therapy. Many recent studies have estimated the role of off-label drug-eluting

\section{AIM OF THE WORK}

This study was designed to evaluate the effect of steroid loaded middle meatal gelfoam sheet on endoscopic sinus surgery outcome regarding middle meatal adhesions and synechiae formation in patients with CRSwNP refractory to medical treatment.

\section{PATIENTS AND METHODS}

Study design:

This was a prospective, randomized, singleblinded, placebo-controlled study comparing the efficacy of triamcinolone-soaked gelfoam nasal packing with that of normal saline nasal packing in 31 patients who had undergone bilateral ESS for bilateral CRSwNP refractory to medical treatment.

The study was conducted in Otorhinolaryngology, Head and Neck Surgery Department - Zagazig University Hospital between April 2018 and June 2019 .

\section{Ethical approval:}

Approval from Institutional Review Board was obtained and an Informed consent from all candidates in the research.

\section{Sample size:}

Assuming that the mean of perioperative sinus endoscopy scale (total score) was $4.65 \pm 4.5$ for triamcinolone group and $7.71 \pm 4.04$ for saline group; the sample size was 62 nasal cavities in 31 patients. By using Open EPI, the confidence interval is $95 \%$ and the power of test is $80 \%$. At the end of ESS, each 
nasal cavity was randomized using a random table to receive either a triamcinolone- or normal salinesoaked gelfoam nasal packing.

\section{Inclusion criteria:}

1- Age above 18 years up to 60 years.

2- Bilateral CRSwNP refractory to medical treatment scheduled for primary endoscopic sinus surgery.

3- Intersinus Lund-Mackay difference of $\leq 1$.

4- None of patients had taken any form of systemic corticosteroids for 2 weeks preoperatively.

\section{Exclusion criteria:}

1- Patients with unilateral nasal pathology.

2- Patients with nasal septal deviation at the level of middle meatus.

3- Patients with aspirin intolerance, asthma or mucociliary disorders.

4- Revision surgery.

5- General medical problems affecting healing process, e.g. uncontrolled diabetes mellitus.

\section{All patients were subjected to the following: \\ A- Questionnaire and full history taking. \\ B- General and local clinical examination. \\ C- Investigations. \\ D- Surgical intervention}

\section{F- Follow Up:}

A- Questionnaire and full history taking: with focus on history of allergy, aspirin intolerance, bronchial asthma, a previous surgery, medications, nasal blockage, headache, loss of smell and taste.

SNOT-22 questionnaire was used in this study to evaluate the quality of life and severity of patients' subjective sinonasal symptoms.

An Arabic version of SNOT-22 questionnaire was prepared and provided to each patient preoperatively and 7, 30 and 60 days after surgery.

\section{B- Full clinical examination: including:}

1.Complete general examination: for vital signs, chest and heart examination.

2. Complete nasal examination: by

- External examination: for swelling and tenderness.

- Anterior rhinoscopy \& nasal endoscopy: showing bilateral enlarged pale bluish turbinate and nasal polypi. anterior rhinoscopy was done using a nasal speculum. Nasal endoscopy was done using $0^{\circ}$ and $30^{\circ}$ endoscope after topical application of decongestant as oxymetazoline drops and anesthesia as xylocaine spray $2 \%$.

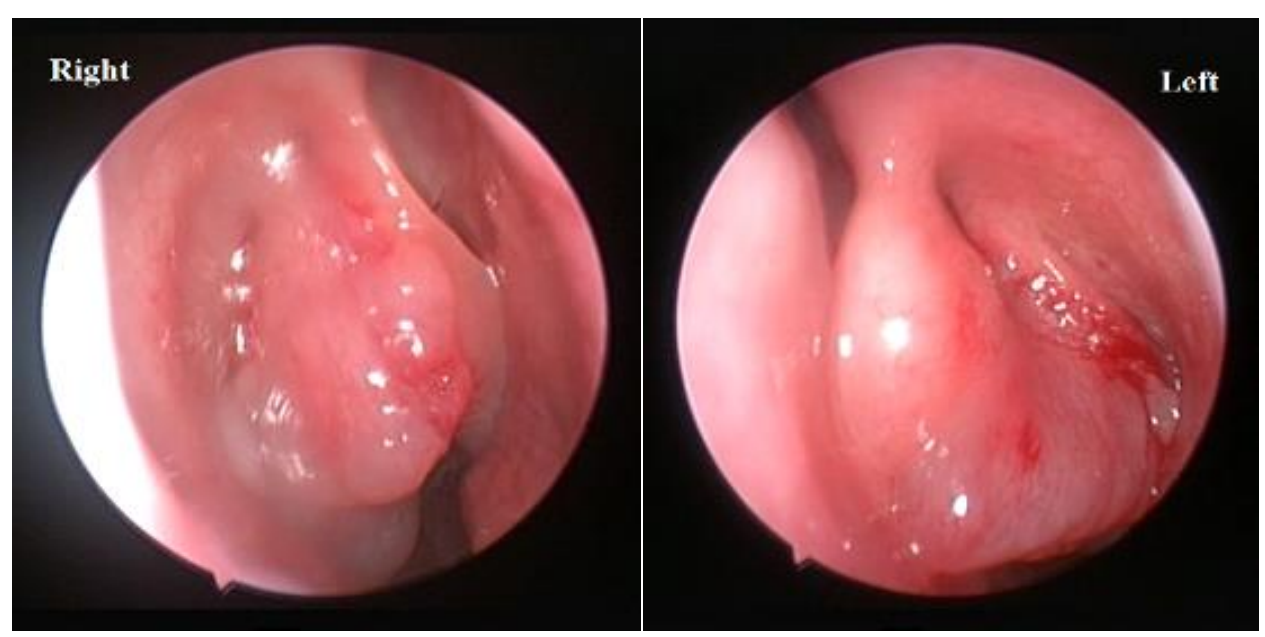

Figure (1): Nasal endoscopy showing bilateral sinonasal polyps. 


\section{C- Investigations:}

- Routine preoperative laboratory investigations: as complete blood picture, liver $\&$ kidney function tests, coagulation profile and blood sugar.

\section{- CT scan:}

All patients were subjected to high resolution CT preoperatively to determine the extent of disease and to detail the anatomy. CT scan was strictly performed after adequate medical treatment and was never performed during acute attacks of rhinosinusitis. We used Lund-MacKay scoring system for preoperative staging of CRS based on CT findings, being simple and reliable.

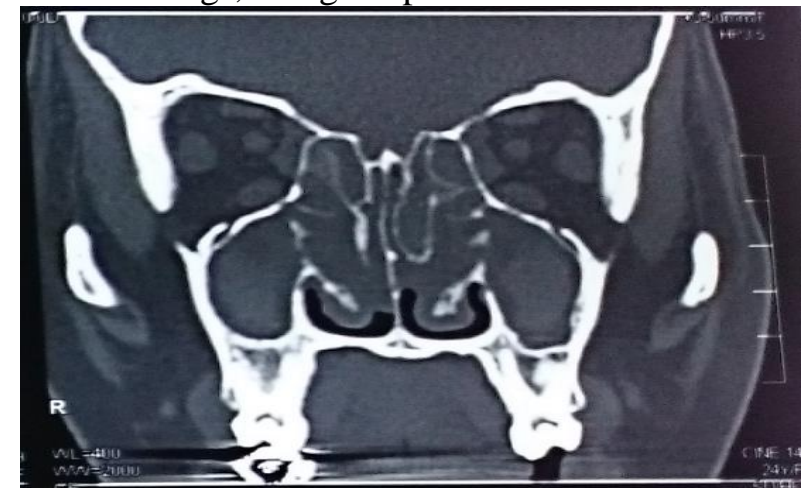

Figure (2): CT scan of PNS, coronal view showing complete opacity of maxillary and anterior ethmoid

\section{E- Surgical intervention:} sinuses bilaterally.

All patients were subjected to bilateral endoscopic sinus surgery under general hypotensive anesthesia with a regular oral endo-tracheal intubation. The degree of surgical intervention depended upon the extent of disease.

At the end of surgery, a gelfoam sheet $(4 \mathrm{~cm})$ soaked with $2 \mathrm{~mL}$ of triamcinolone solution (Epirelefan, $40 \mathrm{mg} / \mathrm{mL}$; E.I.P.I.C.O., $10^{\text {th }}$ of Ramadan city, Egypt) (Figure 41A), was inserted in a middle meatus of one nasal side (Figure 41B), while the contralateral middle meatus received a similar gelfoam sheet soaked with the same amount of normal saline as a control.

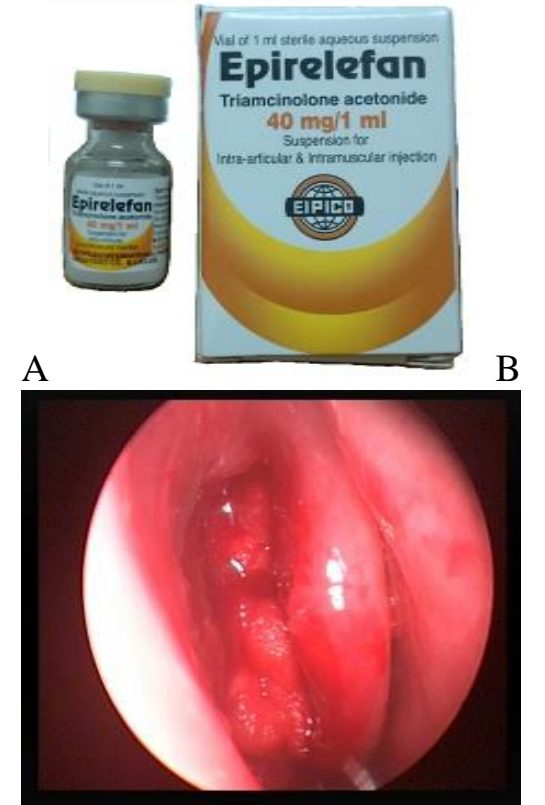

Figure (3): A: Triamcinolone $40 \mathrm{mg} / \mathrm{mL}, \mathrm{B}$ :
Intraoperative application of triamcinolone soaked gelfoam sheet in the middle meatus.

\section{F- Follow Up:}

All patients resumed a 10-days course of oral antibiotics (levofloxacin; $500 \mathrm{mg} / \mathrm{d}$ ).

The nasal packs were removed after 48 hours of surgery. The gelfoam sheets were removed from the middle meati by suction after the $1^{\text {st }}$ postoperative week. Patients were given alkaline nasal douches 1 day after removal of both middle meatal gelfoam sheets.

All Patients visited the outpatient clinic 1, 4 and 8 weeks after surgery. At these visits, the patients were asked about subjective sinonasal symptoms using SNOT-22 questionnaire and they were examined by nasal endoscopy to assess surgical outcomes in the sinonasal cavities using POSE scoring system. The patients underwent debridement of the ethmoid cavities if necessary. Intranasal adhesions if present were divided and crusts and clots were removed.

\section{Statistical analysis}

Recorded data were analyzed using the statistical pac kage for social sciences version 20.0 (SPSS Inc., Chicago, Illinois, USA). Quantitative data were expressed as mean \pm standard deviation (SD). Qualitative data were expressed a $\mathrm{s}$ frequency and percentage.

\section{The following tests were done:}

- Independent-samples t-test of significance was used when comparing between two means.

- Chi-square $\left(\mathrm{x}^{2}\right)$ test of significance was used in order to compare proportions between two qualitative parameters.

- The confidence interval was set to $95 \%$ and the margin of error accepted was set to $5 \%$. The p-value was considered significant as the following:

- Probability (P-value)

- P-value <0.05 was considered significant.

- P-value $<0.001$ was considered as highly significant.

- P-value >0.05 was considered insignificant.

\section{RESULTS}

This study included 31 cases undergoing

ESS with 62 nasal cavities divided into 31 used triamcinolone impregnated nasal pack and 31 used saline impregnated nasal pack.

Table (1): Socio-demographic characteristics of the participants

\begin{tabular}{|c|c|c|}
\hline Variable & \multicolumn{2}{|c|}{ The study group $(31)$} \\
\hline $\begin{array}{c}\text { Age (years) } \\
\text { Mean } \pm S D \\
(\text { Range }) \\
\text { Median }\end{array}$ & \multicolumn{2}{|c|}{$\begin{array}{c}40.9 \pm 18.8 \\
(18-60) \\
34.5\end{array}$} \\
\hline Variable & NO(31) & $\%$ \\
\hline $\begin{array}{c}\text { Sex } \\
\text { Male } \\
\text { Female }\end{array}$ & $\begin{array}{l}20 \\
11\end{array}$ & $\begin{array}{l}64.5 \% \\
35.5 \%\end{array}$ \\
\hline
\end{tabular}

This table showed that the age of the participants ranged from 18 to 60 years with a mean of $40.9 \pm 18.8$ years and $64.5 \%$ of them were males. 
Table (2): Side of nasal cavity in each studied group

\begin{tabular}{|l|c|c|c|}
\hline & Variable & NO(31) & $\%$ \\
\hline Right side & Triamcinolone group & 10 & $32.3 \%$ \\
& Saline group & 21 & $67.7 \%$ \\
\hline Left side & Triamcinolone group & 21 & $67.7 \%$ \\
& Saline group & 10 & $32.3 \%$ \\
\hline
\end{tabular}

This table showed that $67.7 \%$ of the triamcinolone group were left sided while $32.3 \%$ of the saline group were left sided (figure 2).

Table (3): Comparing preoperative Lund-Mackay CT scores in the two studied groups

\begin{tabular}{|c|c|c|c|c|}
\hline Variable & $\begin{array}{c}\text { Triamcinolone group }(31) \\
\text { mean } \pm \text { SD } \\
(\text { Range }) \\
\text { median } \\
\end{array}$ & $\begin{array}{c}\text { Saline group }(31) \\
\text { mean } \pm \mathrm{SD} \\
(\text { Range }) \\
\text { median }\end{array}$ & $\begin{array}{c}\text { M.W } \\
\text { test }\end{array}$ & p-value \\
\hline $\begin{array}{c}\text { Osteomeatal } \\
\text { complex }\end{array}$ & $\begin{array}{c}3.06 \pm 0.7 \\
(1.88-3.86) \\
2.7\end{array}$ & $\begin{array}{c}3.33 \pm 0.6 \\
(2.1-3.9) \\
2.6\end{array}$ & 0.4 & 0.5 \\
\hline Maxillary & $\begin{array}{c}1.31 \pm 0.76 \\
(0.93-1.6) \\
1.12\end{array}$ & $\begin{array}{c}1.29 \pm 0.8 \\
(0.97-1.7) \\
1.1\end{array}$ & 0.6 & 0.7 \\
\hline Ant. ethmoid & $\begin{array}{c}1.89 \pm 0.34 \\
(0.67-2.3) \\
1.4\end{array}$ & $\begin{array}{c}1.88 \pm 0.32 \\
(0.71-2.1) \\
1.5\end{array}$ & 0.2 & 0.4 \\
\hline Post. ethmoid & $\begin{array}{c}0.92 \pm 0.8 \\
(0.64-0.94) \\
0.93\end{array}$ & $\begin{array}{c}0.92 \pm 0.71 \\
(0.67-0.95) \\
0.94\end{array}$ & 0.1 & 0.3 \\
\hline Sphenoid & $\begin{array}{c}0.97 \pm 0.6 \\
(0.84-1.3) \\
0.93\end{array}$ & $\begin{array}{c}0.93 \pm 0.8 \\
(0.87-0.96) \\
0.94\end{array}$ & 0.3 & 0.4 \\
\hline Frontal & $\begin{array}{c}1.34 \pm 0.86 \\
(0.92-1.93) \\
0.83\end{array}$ & $\begin{array}{c}1.42 \pm 0.82 \\
(1.1-1.95) \\
0.84\end{array}$ & 0.6 & 0.5 \\
\hline Total & $\begin{array}{c}9.49 \pm 0.3 \\
(8.9-9.8)\end{array}$ & $\begin{array}{c}9.77 \pm 0.7 \\
(8.5-9.81 .2)\end{array}$ & 0.8 & 0.9 \\
\hline
\end{tabular}

In this table, there was no statistically significant difference in the preoperative Lund-Mackay CT scoring system between triamcinolone and saline groups regarding all items of the score.

Table (4): Comparing triamcinolone and saline groups using total POSE score 1, 4, 8 weeks after surgery

\begin{tabular}{|c|c|c|c|c|}
\hline Variable & $\begin{array}{c}\text { Triamcinolone group (31) } \\
\text { mean } \pm \text { SD } \\
\text { (Range) } \\
\text { median }\end{array}$ & $\begin{array}{c}\text { Saline group (31) } \\
\text { mean } \pm \mathrm{SD} \\
(\text { Range }) \\
\text { median }\end{array}$ & $\begin{array}{l}\text { t- } \\
\text { test }\end{array}$ & p-value \\
\hline $\begin{array}{c}1 \text { week } \\
\text { postoperative }\end{array}$ & $\begin{array}{c}2.93 \pm 0.5 \\
(1-5) \\
2.7 \\
\end{array}$ & $\begin{array}{c}3.2 \pm 0.4 \\
(2-5) \\
3 \\
\end{array}$ & 2.1 & 0.07 \\
\hline $\begin{array}{c}4 \text { weeks } \\
\text { postoperative }\end{array}$ & $\begin{array}{c}3.1 \pm 0.6 \\
(0-5.5) \\
3.1 \\
\end{array}$ & $\begin{array}{c}2.7 \pm 0.7 \\
(0-4) \\
2.6\end{array}$ & 1.9 & 0.09 \\
\hline $\begin{array}{c}8 \text { weeks } \\
\text { postoperative }\end{array}$ & $\begin{array}{c}1.95 \pm 0.4 \\
(0-4) \\
1.4\end{array}$ & $\begin{array}{c}2.46 \pm 0.8 \\
(0-5) \\
2\end{array}$ & 4.1 & $0.01 *$ \\
\hline
\end{tabular}

(Repeated measure ANOVA test)

** Statistically highly significant difference $(\mathrm{P} \leq 0.001),{ }^{*}$ Statistically significant difference $(\mathrm{P} \leq 0.05)$

Regarding comparison between triamcinolone and saline groups, there was a statistically significant difference in total POSE score at 8 weeks post-operative between triamcinolone and saline group with high score in saline group with no statistically significant difference in total POSE score at first and fourth weeks post-operatively between the two groups. 
ejhm.journals.ekb.eg

Table (5): Comparing categories of POSE scoring system 8 weeks after surgery between the two studied groups

\begin{tabular}{|c|c|c|c|c|}
\hline Variable & $\begin{array}{c}\text { Triamcinolone group } \\
(\mathbf{3 1}) \\
\text { mean } \pm \text { SD }\end{array}$ & $\begin{array}{c}\text { Saline group } \\
(\mathbf{3 1}) \\
\text { mean } \pm \text { SD }\end{array}$ & $\begin{array}{c}\text { t- } \\
\text { test }\end{array}$ & p-value \\
\hline $\begin{array}{c}\text { Middle turbinate synaechia / } \\
\text { laterlization }\end{array}$ & $0.57 \pm 0.1$ & $0.23 \pm 0.42$ & 3.3 & $\mathbf{0 . 0 2 *}$ \\
\hline $\begin{array}{c}\text { Middle meatal narrowing / } \\
\text { closure }\end{array}$ & $0.23 \pm 0.5$ & $0.7 \pm 0.43$ & 4.3 & $\mathbf{0 . 0 0 5}^{*}$ \\
\hline Maxillary sinus content & $0.56 \pm 0.3$ & $0.97 \pm 0.45$ & 3.1 & $\mathbf{0 . 0 3}^{*}$ \\
\hline Ethmoid polypoid changes & $0.75 \pm 0.61$ & $1.4 \pm 0.7$ & 3.9 & $\mathbf{0 . 0 2}$ \\
\hline Ethmoid polyposis & $0.43 \pm 0.48$ & $0.91 \pm 0.8$ & 4.1 & $\mathbf{0 . 0 1}$ \\
\hline Ethmoid cavity crusting & $0.41 \pm 0.6$ & $0.54 \pm 0.5$ & 0.9 & 0.7 \\
\hline Mucosal edema \& secretions & $1.32 \pm 0.7$ & $1.6 \pm 0.5$ & 1.7 & 0.6 \\
\hline Sphenoid severity & $0.46 \pm 0.5$ & $0.94 \pm 0.7$ & 2.9 & $\mathbf{0 . 0 3}$ \\
\hline Frontal recess/sinus & $0.56 \pm 0.4$ & $0.87 \pm 0.65$ & 1.1 & 0.9 \\
\hline
\end{tabular}

* Statistically significant difference $(\mathrm{P} \leq 0.05)$

In this table, there was a statistically significant difference between triamcinolone and saline groups in middle turbinate synechia, middle meatal narrowing, sphenoid severity score, ethmoid polyposis, polypoid changes and maxillary sinus content. However, regarding ethmoid cavity crusting, mucosal edema \& secretions and frontal recess/sinus, there was no statistically significant difference between triamcinolone and saline groups.

Table (6): Comparing total SNOT-22 scores preoperative and 8 weeks post-operative in the study group SNOT-22 can't be detected by side, so we only can compare SNOT-22 for each patient as a whole preoperatively and eight weeks postoperatively.

\begin{tabular}{|c|c|c|c|c|}
\hline Variable & $\begin{array}{c}\text { Preoperative } \\
\text { total score (110) }\end{array}$ & $\begin{array}{c}\text { Postoperative total } \\
\text { score (110) }\end{array}$ & $\begin{array}{c}\text { Paired } t \text { - } \\
\text { test }\end{array}$ & p-value \\
\hline $\begin{array}{c}\text { SNOT-22 } \\
\text { mean } \pm \text { SD } \\
\text { range }\end{array}$ & $\begin{array}{c}46.5 \pm 10.4 \\
(21-64)\end{array}$ & $\begin{array}{c}11.9 \pm 3.7 \\
(3-18)\end{array}$ & 15.6 & $\mathbf{0 . 0 0 1} * *$ \\
\hline
\end{tabular}

** Statistically highly significant difference $(\mathrm{P} \leq 0.001)$

In this table, there was highly statistically significant difference in the pre and post-operative total SNOT-22 scores wit $\mathrm{h}$ high improvement.

\section{DISCUSSION}

We assumed that the effects of steroids would be increased if deposited in the middle meatus at adequate concentrations for a longer time. We attempted to deliver more steroids to the most difficult and unreachable areas, such as the frontal and sphenoid sinuses, using a steroidimpregnated absorbable dressing rather than a topical nasal spray.

The present study was conducted on 31 patients who underwent bilateral ESS for CRSwNP. Despite the limited number of patients, our study was a prospective, placebo-controlled trial where at the end of ESS, one nostril was randomly allocated to the triamcinolone group \& received triamcinolone loaded middle meatal gelfoam packing while the contralateral nostril was placed in the control group \& received saline loaded middle meatal gelfoam packing. This approach allowed the steroid impregnated packing to be compared to a placebo in conditions that reduced confounding factors related to patient variability, such as inclusion of both primary and revision bilateral ESS patients and different etiologies of CRSwNP.

There was no statistically significant difference in age or sex where the study included 20 males (64.5\%) and 11 females (35.5\%) and the age of the patients ranged from 18 up to 60 years with a mean of $40.9 \pm 18.8$ years. There is an agreement in our study with Stevens et $\boldsymbol{a l} .{ }^{\left({ }^{(9)}\right.}$ and Fokkens et al. ${ }^{(10)}$ studies regarding the prevalence of sex in patients with CRSwNP. However, Stevens et al. (9) reported that females with CRSwNP had more severe disease than males.

We used SNOT-22 questionnaire in the present study to evaluate the quality of life and severity of patients' subjective symptoms pre- and post-operatively. The mean of total SNOT-22 score was $46.5 \pm 10.4$ before surgery and $11.9 \pm 3.78$ weeks after surgery indicating that there was a highly statistically significant difference in the total SNOT-22 scores pre and post-operatively $(P$ $<0.001$ ) with high improvement in patients' 
quality of life. The present study agree with Le $\boldsymbol{e t}$ al. (11) study, which concluded that ESS significantly improves quality of life outcomes in CRSwNP.

In the present study, there was no statistically significant difference in the total preoperative Lund-Mackay CT scores between triamcinolone and saline groups, $9.49 \pm 0.3$ vs 9.77 \pm 0.7 respectively.

We used the POSE scoring system to evaluate postoperative objective outcomes between triamcinolone \& saline groups and to evaluate each sinus individually, because it is more detailed and sensitive to treatment-related changes. POSE scoring system was introduced to promote face validity and responsiveness to change by providing richer measures of the inflammation in the ethmoid cavity, scarring and obstruction in outflow, as well as assessment of secondary sinuses ${ }^{(12)}$. In the present study, the mean of total POSE score at 8 weeks after surgery was $1.95 \pm 0.4$ for triamcinolone group and $2.46 \pm 0.8$ for saline group indicating that there was a statistically significant difference in the total POSE scores between triamcinolone and saline groups at 8 weeks after surgery $(P<0.01)$ with a lower score of triamcinolone group. However, there was no statistically significant difference in the total POSE scores between the 2 groups at 1 and 4 weeks after surgery. With respect to categories of POSE scoring system at 8 weeks after surgery. There was a statistically significant difference between triamcinolone and saline groups in reduction of: middle turbinate synechia $0.57 \pm 0.1$ vs $0.23 \pm 0.42$ $(P=0.02)$, middle meatal narrowing $0.23 \pm 0.5$ vs $0.7 \pm 0.43(P=0.005)$, sphenoid severity $0.46 \pm 0.5$ vs $0.94 \pm 0.7(P=0.03)$, ethmoid polyposis $0.43 \pm$ 0.48 vs $0.91 \pm 0.8(P=0.01)$, ethmoid polypoid changes $0.75 \pm 0.61$ vs $1.4 \pm 0.7(P=0.02)$ and maxillary sinus content $0.56 \pm 0.3$ vs $0.97 \pm 0.45$ $(P=0.03)$. However, regarding ethmoid cavity crusting, ethmoid mucosal edema $\&$ secretion and frontal recess/sinus, there was no statistically significant difference between triamcinolone and saline groups. These statistically significant results (except middle meatal narrowing) agree with Hwang et al. ${ }^{(4)}$ study that was conducted on 22 patients underwent bilateral ESS for CRSwNP. This study found that triamcinolone-soaked, absorbable nasal packing significantly reduced the middle meatal synechiae, ethmoid polypoid changes, and sphenoid sinus severity at 8 weeks after surgery. In addition, the present study agrees with Marple et al. ${ }^{(13)}$, Promentilla et al. ${ }^{(14)}$ and Zhao et al. ${ }^{(15)}$ studies.

Murr et al. ${ }^{(8)}$ and Marple et al. (13) established 2 randomized controlled trials (RCTs) and assessed the role of mometasone furoate with PROPEL spacer vs plain PROPEL spacer using the contralateral nasal cavity as control. Murr et al. ${ }^{(8)}$ observed that the nasal cavity with the mometasone furoate PROPEL spacer had significantly less dense and severe adhesions compared to control $(P$ $<0.0313)$. Marple et al. ${ }^{(13)}$ showed a statistically significant reduction in profound and severe adhesions $(P=0.039)$. Promentilla et al. (14) established a randomized controlled trial to evaluate the effects of Dexamethasone versus saline impregnated absorbable nasal packing on post-FESS outcome in patients with CRSwNP and found that dexamethasone impregnated absorbable nasal packing affords better postoperative outcomes: less synechiae, edema, secretions and crusting than saline impregnated absorbable packing. Zhao et al. ${ }^{(15)}$ randomized CRSwNP patients to postoperatively receive mometasone furoate soaked nasopore in a nasal cavity and saline soaked nasopore in the contralateral cavity as control and found that mometasone furoate soaked nasopore improved the endoscopic appearance in the healing process.

In contrast, the present study does not agree with Cote and Wright ${ }^{(12)}$, Xu et al. ${ }^{(16)}$ and Sabarinath et al. ${ }^{(17)}$ studies.

Cote and Wright ${ }^{(\mathbf{1 2})}$ evaluated the role of triamcinolone with nasopore vs nasopore with saline using the contralateral nasal cavity as control and observed that there was no statistically significant trend toward reduced adhesions in the experimental side $(P<0.25)$. However, the study suggested a significant improvement in early postoperative healing in the experimental side and it is associated with improved healing up to 6 months postoperatively. Xu et al. ${ }^{(16)}$ randomized CRSwNP patients post-FESS to receive middle meatal Nasopore bilaterally, impregnated with saline as control or triamcinolone (experimental arm). This study showed that triamcinolone impregnated biodegradable nasal dressing was not related to the improvement of subjective symptoms compared to the control arm. However, triamcinolone impregnated dressing had a significant advantage over saline impregnated dressing concerning improvement of olfactory function and postoperative wound healing during the short period of follow up. Sabarinath et al. ${ }^{(17)}$ randomized CRS patients after FESS to receive middle meatal merocel bilaterally, impregnated with saline as control or triamcinolone (experimental arm). This study found a significant reduction in the mucosal edema and crusting in the experimental arm, suggesting the efficacy of topically applied triamcinolone in overcoming the early postoperative challenges in CRS patients. 
However, there was no significant reduction in nasal discharge or early recurrence.

In the present study, we detected treatment effects based on endoscopic findings rather than symptoms. It is important to observe that postoperative endoscopic findings in patients with CRSwNP frequently do not correspond to symptoms, especially in the early stages of recurrence ${ }^{(\mathbf{1 8})}$.

Hong et al. ${ }^{(19)}$ reported that triamcinolonesoaked nasal dressings suppressed serum cortisol level during the early postoperative period and this systemic effect normalized gradually 10 days after the operation. Otherwise, it is considered as a relatively safe treatment modality ${ }^{(4)}$.

\section{CONCLUSION}

Results of our study demonstrated that the steroid loaded middle meatal gelfoam sheet has a role in minimizing middle meatal adhesions and synechiae formation after endoscopic sinus surgery for patients with CRSwNP.

\section{REFERENCES}

1. Tan BK, Chandra RK, Pollak J et al. (2013): Incidence and associated premorbid diagnoses of patients with chronic rhinosinusitis. J Allergy Clin Immunol., 131: 1350-60.

2. Bateman ND, Fahy C, Woolford TJ (2003): Nasal polyps: still more questions than answers. J Laryngol Otol., 117: 1-9.

3. Neubauer PD, Schwam ZG, Manes RP (2016): Comparison of intranasal fluticasone spray, budesonide atomizer, and budesonide respules in patients with chronic rhinosinusitis with polyposis after endoscopic sinus surgery. Int Forum Allergy Rhinol., 6: 233-237.

4. Hwang CS, Al Sharhan SS, Kim BR et al. (2018): Randomized controlled trial of steroid- soaked absorbable calcium alginate nasal packing following endoscopic sinus surgery. The Laryngoscope, 128 (2): 311-316.

5. Otto KJ, DelGaudio JM (2010): Operative findings in the frontal recess at time of revision surgery. Am J Otolaryngol., 31: 175-180.

6. Musy PY, Kountakis SE (2004): Anatomic findings in patients undergoing revision endoscopic sinus surgery. Am J Otolaryngol., 25: 418- 422.

7. Rudmik L, Soler ZM, Orlandi RR et al. (2011): Early postoperative care following endoscopic sinus surgery: an evidence-based review with recommendations. Int Forum Allergy Rhinol., 1 (6): 417-30.
8. Murr AH, Smith TL, Hwang PH et al. (2011): Safety and efficacy of a novel bioabsorbable, steroid-eluting sinus stent. Int Forum Allergy Rhinol., 1 (1): 23-32.

9. Stevens WW, Schleimer RP, Kern RC (2016): Chronic Rhinosinusitis with Nasal Polyps. J Allergy Clin Immunol Pract., 4 (4): 565-572.

10.Fokkens WJ, Lund VJ, Mullol J et al. (2012): European position paper on rhinosinusitis and nasal polyps. A summary for otorhinolaryngologists. Rhinology, 50: 1-12.

11.Le PT, Soler ZM, Jones R et al. (2018): Systematic review and meta-analysis of SNOT-22 outcomes after surgery for chronic rhinosinusitis with nasal polyposis. Otolaryngology-Head and Neck Surgery, 159 (3): 414423.

12. Cote DWJ, Wright ED (2010): Triamcinoloneimpregnated nasal dressing following endoscopic sinus surgery: a randomized, double-blind, placebo controlled trial. Laryngoscope, 120: 1269-1273.

13. Marple BF, Smith TL, Han JK et al. (2012): Advance II: a prospective, randomized study assessing safety and efficacy of bioabsorbable steroid-releasing sinus implants. Otolaryngol Head Neck Surg., 146 (6): 100411.

14.Promentilla SMA, Onofre RDC, Campomanes BSA (2016): Effects of Dexamethasone versus SalineImpregnated Nasal Packing on the Postoperative Outcome of Patients with Chronic Rhinosinusitis and Nasal Polyps after Endoscopic Sinus Surgery: A Randomized Controlled Trial. PhilipPine Journal of otolaryngology-head and neck Surgery, 31.1: 10-13.

15.Zhao KQ, Yu YQ, Yu HM (2018): Effects of mometasone furoate-impregnated biodegradable nasal dressing on endoscopic appearance in healing process following endoscopic sinus surgery: a randomized, double-blind, placebo-controlled study. Int Forum Allergy Rhinol., 8: 1233-1241.

16.Xu J, Park SJ, Park HS et al. (2016): Effects of triamcinolone- impregnated nasal dressing on subjective and objective outcomes following endoscopic sinus surgery. Eur Arch Otorhinolaryngol., 273: 4351- 4357.

17. Sabarinath V, Harish MR, Divakaran S (2017): Triamcinolone impregnated nasal pack in endoscopic sinus surgery: our experience. Indian Journal of Otolaryngology and Head \& Neck Surgery, 69 (1): 8892.

18. Bhattacharyya $N$ (2006): Clinical and symptom criteria for the accurate diagnosis of chronic rhinosinusitis. Laryngoscope, 116: 1-22.

19. Hong SD, Kim JH, Dhong HJ et al. (2013): Systemic effects and safety of triamcinolone-impregnated nasal packing after endoscopic sinus surgery: a randomized, double-blinded, placebo-controlled study. Am J Rhinol Allergy, 27: 407-410. 